\section{An Enzymatic Assay Convenient for the Control of Aprotinin Levels During Proteinase Inhibitor Therapy}

\author{
M. Jochum ${ }^{1}$, V. Jonáková ${ }^{1 *}$, H. Dittmer ${ }^{2}$, and H. Fritz ${ }^{1}$ \\ ${ }^{1}$ Abteilung für Klinische Chemie und Klinische Biochemie \\ in der Chirurgischen Klinik Innenstadt \\ der Universität München, Nussbaumstraße 20, \\ D-8000 München 2 \\ ${ }^{2}$ Chirurg. Klinik Großhadern der Universität München, \\ D-8000 München 70, Federal Republic of Germany
}

\section{Ein enzymatischer Test zur Kontrolle der Aprotininspiegel bei der Proteinaseinhibitor-Therapie}

Introduction. Administration of the broad specific proteinase inhibitor aprotinin (Trasylol) is recommended as part of the therapeutic regimen of various diseases, e.g. in shock syndromes, hyperfibrinolysis or acute pancreatitis [1]. However, the attempt to demonstrate clinical effectiveness of aprotinin therapy by prospective controlled clinical trials has proved to be extremely difficult, probably due to the lack of an assay system allowing a reliable estimation of effective inhibitor concentrations in plasma [1]. We have established a chromogenic peptide substrate assay convenient for monitoring the inhibitory effectiveness of aprotinin in plasma samples of patients undergoing inhibitor therapy.

\footnotetext{
* Research fellowship from Humboldt-Stiftung, Institute of Molecular Genetics, Prague, CSSR

Offprint requests to: $\mathrm{M}$. Jochum
}

Assay Principle. In contrast to endogenous plasma proteinase inhibitors, aprotinin (Trasylol) is a very potent immediate inhibitor of porcine pancreatic kallikrein (tissue kallikrein). Due to acid treatment of plasma samples obtained after i.v. infusion of aprotinin in vivo or addition of the inhibitor in vitro, aprotinin is the only measurable tissue kallikrein inhibitor in these specimens. After incubation of acid-treated plasma with tissue kallikrein in excess over aprotinin, the remaining amount of the enzyme is determined by its amidolytic activity on the substrate H-D-Val-Leu-Arg-pNA (S-2266). The rate at which pNA is released is measured photometrically at $405 \mathrm{~nm}$ with the initial rate method. Under the given conditions the substrate recognizes exclusively the tissue kallikrein applied.

Reagents. $S-2266$ is manufactured by $\mathrm{AB}$ Kabi Diagnostica, Stockholm, Sweden. Porcine pancreatic kallikrein is available as a lyophilized research product from Bayer AG, Wuppertal-Elberfeld, FRG: Kininogenase Standard Pt. 2208 L ( $512.5 \mathrm{KU} /$ ampoule). A stock solution of $1 \mathrm{KU} / \mu \mathrm{l}$ is prepared by dissolving the residue in sterile $0.9 \% \mathrm{NaCl}$ solution adjusted to pH 7.5 with triethanolamine. Aprotinin (Trasylol) for preparation of the standard curve is purchased as a sterile isotonic solution (ampoules of $200,000 \mathrm{KIU} / 10 \mathrm{ml}, \mathrm{pH}$ ) from Bayer AG, Leverkusen, FRG.

Procedure. 1. Acid Treatment of Plasma. Normal plasma or patients' plasma is incubated for $10 \mathrm{~min}$ at $25^{\circ} \mathrm{C}$ with an equal volume of $3 \%(\mathrm{w} / \mathrm{v})$ perchloric acid. After centrifugation the supernatant is neutralized with $5 \mathrm{M} \mathrm{K}_{2} \mathrm{CO}_{3}$, kept at $4-8^{\circ} \mathrm{C}$ for further $30 \mathrm{~min}$ and thereafter centrifuged again. The resulting supernatant is frozen at $-20^{\circ} \mathrm{C}$ or below.

2. Standard Curve. All samples are acid-treated before further use. Standard samples are made up from normal plasma supplemented with aprotinin $(100 \mathrm{KIU} / \mathrm{ml}$ acid-treated plasma

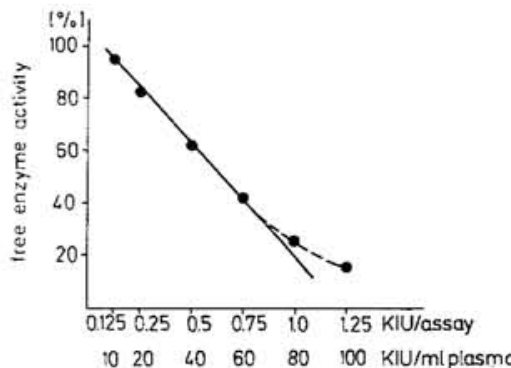

Fig. 1. Standard curve for the determination of aprotinin in plasma (details see text)

corresponding to $200 \mathrm{KIU} / \mathrm{ml}$ untreated plasma) by dilution of this stock solution with aprotinin-free normal plasma.

3. Photometric Assay. The reaction mixture is prepared by pipetting the samples in the following order into thermostated $\left(37^{\circ} \mathrm{C}\right) 1$-ml-cuvettes placed in a photometer: $855 \mu \mathrm{l}$ Tris buffer $(0.2 \mathrm{M}, \mathrm{pH} 8.2), 25 \mu \mathrm{l}$ acid-treated normal plasma ("blank") or aprotinin-containing plasma (standard or patients' samples), and $20 \mu \mathrm{l}$ kallikrein solution $(1 \mathrm{KU})$. After $5 \mathrm{~min}$ incubation at $37^{\circ} \mathrm{C}$ $100 \mu \mathrm{l} \mathrm{S}-2266$ solution $(1.5 \mathrm{mM})$ is added and the linear increase in absorbance at $405 \mathrm{~nm}$ read continuously for at least $3 \mathrm{~min}$. The free enzyme activity $(\Delta \mathrm{A} / \mathrm{min})$ of the sample is calculated in percent of the "blank". The percent of free enzyme activities of the standard samples are plotted against their concentrations of aprotinin, and the inhibitory activity of aprotinin in the patients' plasma is calculated from this standard curve.

Results and Discussion. Evaluation of the Assay. According to the standard curve (Fig. 1) the lowest accurately measurable amount of aprotinin is about 20 kallikrein inhibitor units (KIU) $/ \mathrm{ml}$ plasma (before acid treatment), i.e. $0.25 \mathrm{KIU}$ per assay. If the aprotinin amount exceeds $0.75-1.0 \mathrm{KIU}$ per assay, plasma samples should be diluted as follows. Since kallikrein activity is elevated 1.23 -fold $(n=90 ;$ C.V. $=7.2 \%)$ by addition of acid- treated normal plasma, all dilutions of aprotinin-containing plasma samples must be made by aprotinin-free plasma. Thereby always the same amount of plasma $(25 \mu \mathrm{l})$ is added to the test system. Dilution with buffer or isotonic saline solution instead of plasma yields inhibitor concentrations which are too low. For $40 \mathrm{KIU} / \mathrm{ml}$ the within-run imprecision was $1.8-10.8 \%$ in 8 series, the between-series imprecision $(n=8) 4.4 \%$. The recovery for $20-80 \mathrm{KIU} / \mathrm{ml}$ was $90-125 \%$. The acid-treated samples were stable for at least 1 month at $-20^{\circ} \mathrm{C}$ and for 6 months at $-70^{\circ} \mathrm{C}$. No influence by repeated freezing and thawing (10 times) could be observed. Plasma samples without acid treatment cannot be used because of a too high and irregular stimulation of the kallikrein activity in the assay system.

Clinical Application. Continuous i.v. infusion of $250,000 \mathrm{KIU} / \mathrm{h}$ in polytraumatized patients resulted in a mean plasma concentration of $45 \mathrm{KIU} / \mathrm{ml}$. This level is equivalent to approx. $1 \mu \mathrm{M}$ aprotinin and thus close to the concentration of the endogenous $\alpha_{2}$-plasmin inhibitor level $(0.9 \mu \mathrm{M})$ in normal plasma. The aprotinin plasma level achieved during inhibitor therapy caused a significant reduction of the fibrinogen split products compared to untreated but equally severely injured patients indicating a beneficial effect by suppressing systemic fibrinolysis.

Conclusion. Estimation of aprotinin in plasma with the described amidolytic assay can be achieved within $70-80 \mathrm{~min}$ and is, therefore, convenient as a bedside-control of high dose proteinase inhibitor therapy. Moreover, an ELISA for aprotinin developed simultaneously (Müller-Esterl et al. this issue) allows the detection of up to $0.2 \mathrm{KIU} / \mathrm{ml}$ within $4 \mathrm{~h}$ and is suitable, therefore, for special purposes, e.g. retrospective studies and low dose inhibitor therapy.

\section{References}

1. Fritz H, Wunderer G (1983) Drug Res 33(I):4, pp 479-494 